\title{
Ocorrência de Coliformes Termotolerantes e Escherichia Coli em Carnes com Selo de Inspeção Municipal e Federal Comercializadas em Limoeiro do Norte-CE
}

Monique Ellen Torres da Silva (I), Monique de Oliveira Maia (I), Germana Conrado de Souza (I), Antônia Lucivânia de Sousa Monte (I), Marlene Nunes Damaceno (I), Maria Gilnara Lima Bandeira (I), Anaklaudia Sombra Santos (I), Francisco Jorge Nogueira de Moura

(I) IFCE - Instituição Federal de Educação, Ciência e Tecnologia (Rua Estevão Remígio, 1145, Centro, Limoeiro do Norte. CEP: 62930-000)

\section{Resumo}

Os produtos alimentícios podem se tornar veículos de agentes patogênicos ao homem, através de contaminação e multiplicação de microbiota, principalmente os de origem animal como as carnes em geral, que são facilmente contaminados antes, durante e após o abate bem como nas feiras livres, açougues e supermercados. Objetivou-se com esse trabalho verificar a ocorrência de coliformes termotolerantes e Escherichia coli em carnes com selo de inspeção municipal (SIM) e federal (SIF) comercializadas em Limoeiro do Norte-CE. As amostras de carnes bovinas com os respectivos selos de inspeção foram adquiridas no comércio de Limoeiro do Norte CE e foram analisadas 5 amostras de cada uma, em duas repetições. As carnes bovinas no ato de sua aquisição foram acondicionadas em sacos plásticos novos e esterilizadas, em seguida foram encaminhadas imediatamente ao Laboratório de Microbiologia de Alimentos, do Instituto Federal de Educação, Ciência e Tecnologia do Ceará, Campus Limoeiro do Norte, onde foram realizadas as análises microbiológicas, para determinação de Coliformes a $45^{\circ} \mathrm{C}$ com confirmação de Escherichia coli.

\footnotetext{
Referência:

Monique Ellen Torres da Silva, Monique de Oliveira Maia, Germana Conrado de Souza, Antônia Lucivânia de Sousa Monte, Marlene Nunes Damaceno, Maria Gilnara Lima Bandeira, Anaklaudia Sombra Santos, Francisco Jorge Nogueira de Moura.Ocorrência de Coliformes Termotolerantes e Escherichia Coli em Carnes com Selo de Inspeção Municipal e Federal Comercializadas em Limoeiro do Norte-Ce. In: Anais do 12을 Congresso Latinoamericano de Microbiologia e Higiene de Alimentos - MICROAL 2014 [= Blucher Food Science Proceedings, num.1, vol.1]. São Paulo: Editora Blucher, 2014. 
Para as contagens de coliformes a $45^{\circ} \mathrm{C}$ das amostras de carne SIF, três amostras apresentaram contagens mínima de coliformes ( $<3 \mathrm{NMP} /$ $\mathrm{g}$ ), e as outras duas apresentaram contagem de 4 e $3 \mathrm{NMP} / \mathrm{g}$, além disso, em uma amostra foi confirmada a presença da bactéria Escherichia coli. Para as amostras de carne SIM, as amostras apresentaram respectivamente valores de $2,8 \times 10,2,1 \times 10,2,8 \times 10$, $1,1 \times 10^{3} \mathrm{e} 1,1 \times 10 \mathrm{NMP} / \mathrm{g}$, todas sendo positivas para bactéria Escherichia coli. A bactéria Escherichia coli é encontrada no trato gastrointestinal de animais de sangue quente, e quando a obtenção da carne não é realizada de modo satisfatório, essas bactérias podem permanecer nas carcaças durante o processamento e contaminar as carnes. Conclui-se assim que as carnes com selo de inspeção federal apresentaram qualidade superior as carnes com selo de inspeção municipal, o que já era esperado visto que, a rigorosidade em termo de qualidade é mais exigida na SIF. Porém é necessário haver o controle da qualidade em toda as etapas de produção, até a chegada à mesa do consumidor, pois a proliferação de bactérias patogênicas ocorre rapidamente se o produto for manipulado e armazenado em temperatura e condições não ideais.

Palavras-Chave: Alimentos, controle de qualidade, inspeção, microbiológica Agência de Fomento: CAPES; FUNCAP 